25.00 .17

УДК 622.279 .51

Саранча A.B.,

Левитина Е.E., Есиков C.H.
Введение.

РАЗРАБОТКА И ЭКСПЛУАТАЦИЯ НЕФТЯНЫХ И ГАЗОВЫХ МЕСТОРОЖДЕНИЙ

Тюменский индустриальный университет saranchaav@tyuiu.ru

\section{ПРИМЕНЕНИЕ РАЗЛИЧНЫХ ТЕХНОЛОГИЙ ЭКСПЛУАТАЦИИ САМОПРОИЗВОЛЬНО ОСТАНАВЛИВАЮЩИХСЯ ГАЗОВЫХ СКВАЖИН НА МЕСТОРОЖДЕНИЯХ КРАЙНЕГО СЕВЕРА}

Текущее состояние разработки сеноманских залежей месторождений ЯНАО, разрабатываемых уже более 30 лет, связано со значительным снижением пластового давления относительно первоначального, и как следствием снижением продуктивности добывающих скважин. В результате ухудшают условия выноса с забоя газовых скважин поступающей из пласта конденсирующейся воды. Накопление воды на забое скважин приводит к увеличению фильтрационных сопротивлений, дальнейшему снижению продуктивности и в итоге к самопроизвольной остановке скважин.

Материалы и методы исследований. Без проведения специальных мероприятий, направленных на поддержание режима эксплуатации таких скважин, дальнейшая добыча из них невозможна. На сегодняшний день на месторождениях ЯНАО прошли применение такие мероприятия как: периодическая продувка скважин в атмосферу; обработка забоя твердыми и жидкими поверхностно-активными веществами; замена лифтовых труб на меньший диаметр; применение плунжерного лифта (летающий клапан); циклическая закачка сухого газа в затрубное пространство; применение мобильных компрессорных установок и использование концентрического лифта.

Результаты исследований и их обсуждение. Важнейший недостаток технологии концентрического лифта (КЛК), когда применяются металлические трубы, заключается в необходимости глушения скважины и вытекающее негативное воздействие на призабойную зону пласта (ПЗП) технологической жидкостью, а также длительный простой со значительными капитальными издержками. В настоящее время в ОАО «Псковгеокабель» разработаны и изготовлены полимерная армированная труба и устройство для её спуска в скважину без глушения, которая спускается одним отрезком. Данный комплекс проходил апробацию на Уренгойском месторождении. Результаты ГДИ скважин показали, что после спуска КЛК коэффициент фильтрационного сопротивления ПЗП практически не изменился.

Выводы.

Наиболее перспективными технологиями по эксплуатации самопроизвольно останавливающихся газовых скважин являются: закачка ПАВ на забой, применение модульных компрессорных установок, позволяющих регулировать технологический режим работы скважин независимо от давления на входе в ДКС и применение концентрического лифта с армированными полимерными трубами без глушения скважины.

Ключевые слова: газовые скважины, сеноманские залежи, дебит газа, удаление жидкости из скважин, самозадавливание скважин. 
Sarancha A.V., Levitina E.E., Esikov S.N.

Tyumen Industrial University, saranchaav@tyuiu.ru

\section{THE USE OF DIFFERENT TECHNOLOGIES OPERATE SPONTANEOUSLY STOPPING GAS WELLS ON THE FIELDS OF THE FAR NORTH}

Introduction. The current state of the development of Cenomanian deposits is associated with a significant decrease in reservoir pressure relative to the original and as a result of a decrease in the productivity of producing wells. As a result, the conditions of removal from the bottom of wells coming from the formation and condensing water worsen. The accumulation of water leads to an increase in filtration resistance, a further decrease in productivity and, as a result, to the spontaneous shutdown of wells.

\section{Materials and methods}

of research. Without special geological and technical measures aimed at maintaining the operation of such wells, further operation is impossible. To date, the fields of Western Siberia have found the use of such measures as: periodic purging of wells with the release of gas into the atmosphere; treatment of well bottom solid and liquid surfactants; replacement of tubing for pipes of smaller diameter; the use of a plunger Elevator; cyclic injection of dry gas into the annular space; application of modular compressor units and use of concentric lift.

Results and Discussion. The most important drawback of the concentric lift technology, when metal pipes are used, is the need to kill the well and the resulting negative impact on the bottom-hole zone of the reservoir by the process fluid, as well as a long downtime of the well with significant capital costs. Currently JSC «PskovGeoKabel» designed and manufactured polymer reinforced pipe and device for its descent into the well without killing a single cut. The developed complex was tested at the Urengoy field. The results of gas-hydrodynamic studies of wells showed that after the descent of the concentric lift column, the coefficient of filtration resistance of the bottom-hole formation zone practically did not change.

Conclusion. The most promising technical solutions for the operation of spontaneously stopping gas wells are: injection of surfactants at the bottom, the use of modular compressor units that allow to regulate the technological mode of the wells regardless of the pressure at the entrance to the DKC and the use of a concentric Elevator with reinforced polymer pipes without killing the well.

Keywords: gas well, of the Cenomanian deposits, gas flow rate, the liquid removal from the wells self-tapping wells. 


\section{ВВЕДЕНИЕ}

Промышленная добыча газа из сеноманских залежей в Ямало-Ненецком автономном округе введется с 1972 года, когда в разработку было введено Медвежье месторождение. Далее в 1978 году вводится в разработку сеноманская залежь Уренгойского, а в 1986 году Ямбургского месторождения. Благодаря вводу этих трех гигантских месторождений в 1992 году добыча газа достигла 511 млрд м $^{3}$, из которых 427 млрд м³ или $84 \%$ приходилось на три вышеупомянутых месторождения (рис. 1).

В 2018 году отбор от начальных геологических запасов газа по сеноманским залежам Медвежьего, Ямбургского и Уренгойского месторождения превысила восьмидесятипроцентную отметку. Текущее состояние разработки вышеупомянутых объектов связано со значительным падением пластового давления относительно первоначального и как следствием снижением продуктивности добывающих скважин. Снижение пластового давления и дебита газа ухудшают условия выноса с забоя скважин поступающей из пласта конденсирующейся воды. Вследствие недостаточности скорости восходящего потока, капли воды стекают на забой скважины и накапливаются там, формируя противодавление на пласт. Накопление воды приводит к увеличению фильтрационных сопротивлений, дальнейшему снижению продуктивности и в итоге к самопроизвольной остановке скважин. Без проведения специальных мероприятий, направленных на поддержание режима работы таких скважин, дальнейшая эксплуатация невозможна.

На сегодняшний день применяются следующие мероприятия:

периодическая продувка скважин с выпуском газа в атмос-
феру;
обработка забоя скважин твердыми и жидкими поверхнос-
- $\quad$ тно-активными вешествами (ПАВ);
замена насосно-компрессорных труб (НКТ) на трубы мень-
шего диаметра;
применение плунжерного лифта;
- $\quad$ пиклическая закачка сухого газа в затрубное пространство;
- $\quad$ применение модульных компрессорных установок.
использование концентрического лифта;

\section{МАТЕРИАЛЫ И МЕТОДЫ ИССЛЕДОВАНИЙ}

Рассмотрим более подробно апробированные и перспективные решения позволяющие эксплуатировать скважины на завершающем этапе разработки сеноманских залежей Крайнего Севера, а также ограничения по их применению. 


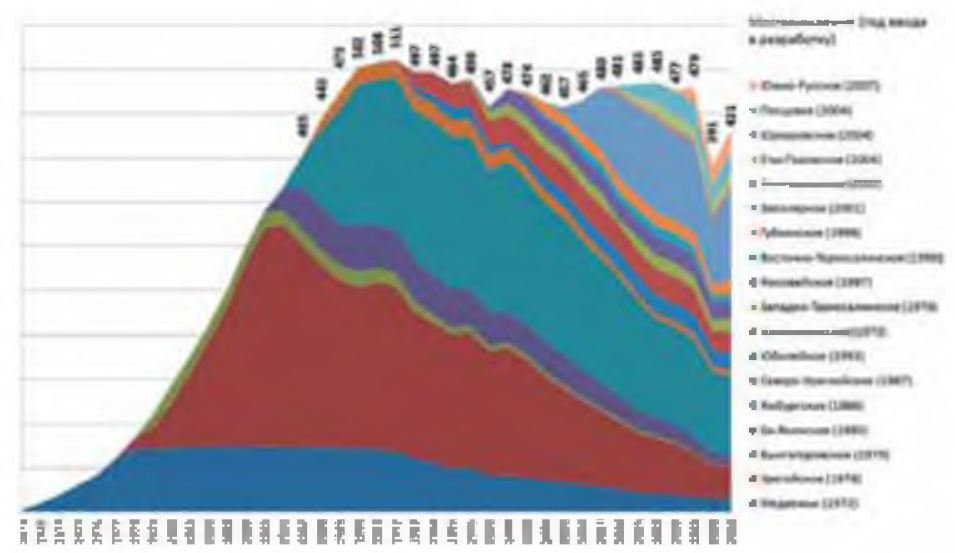

Pис 1.

Динамика добычи газа по сеноманскому комплексу ЯНАО.

Fig. 1. Dynamics of gas production in the cenomanian complex YNAO.

\section{Периодическая продувка скважин с выпуском газа в атмосферу}

Наиболее простой технологией удаления жидкости из скважин являются технологические продувки, которые осуществляются через факельную линию, при этом давление на устье скважины уменьшается, а дебит и, соответственно скорость газа на забое и в лифтовой колонне возрастает. С увеличенным дебитом скважина должна работать минимум 30-50 мин. Периодичность проведения продувок зависит от интенсивности скопления жидкости на забое и в лифтовой колонне, по отдельным скважинам такие работы необходимо проводить раз в 3-4 суток [1]. Данное мероприятие с точки зрения экологии считается не приемлемым, а также связано с безвозвратными потерями газа в атмосферу.

\section{Обработка эксплуатационных скважин составами ПАВ}

На Медвежьем месторождении применяются три вида технологий удаления жидкости из скважины с применением ПАВ: обработка забоев скважин твердыми ПАВ, обработка призабойной зоны пласта (ПЗП) жидкими ПАВ и обработка ПЗП жидким ПАВ с последующей продавкой в пласт метанола. Во всех случаях ПАВ доставляют на забой скважины, где происходит вспенивание воды и последующее ее удаление.

Применение ПАВ имеет некоторые ограничения. Во-первых, во время применения ПАВ на скважине необходимо непосредственное присутствие 
оператора, который должен иметь возможность беспрепятственного доступа к скважине (наличие дорог и т.п.). Во-вторых, установлено, что при скоростях газа в эксплуатационной колоне (ниже башмака НКТ) более $2 \mathrm{~m} / \mathrm{c}$ происходит разрушение пенистой структуры, вследствие чего применение ПАВ становится бессмысленным. В-третьих, для создания условий барботажа жидкости необходим значительный интервал перфорации, при этом в скважине практически должен отсутствовать зумпф.

\section{Замена НКТ на трубы меньшего диаметра}

Замена труб лифтовой колонны на трубы меньшего диаметра проводится для создания условий выноса воды из лифтовых колонн. Отрицательным моментом является то, что замена НКТ всегда сопровождается снижением дебита скважин. Проводимые ранее анализы замены труб лифтовых колонн на трубы меньшего диаметра на сеноманских залежах месторождений ЯНАО показали относительную эффективность меры только на скважинах, работающих с дебитами газа, значительно меньшими критического на $30 \div 80 \%$. Поэтому основной задачей в процессе разработки должно является продление максимально возможного срока эксплуатации скважин по колоннам из труб большого диаметра. Минимальный дебит газа, обеспечивающий надежную эксплуатацию скважин с НКТ диаметрами 168, 114, 89, 73 мм составляет соответственно - 150, 70, 38, 28 тыс. м. куб/сут. [1].

\section{Эксплуатация скважин с использованием плунжерного лифта}

Установки плунжерного лифта могут быть непрерывного или периодического действия. Первые из них подразумевают постоянное перемещение плунжера в колонне НКТ, вторые - с остановками плунжера в лубрикаторе скважины. Управление установкой плунжерного лифта периодического действия осуществляется с помощью контроллера и клапана-отсекателя, что позволяет регулировать время выноса жидкости из скважины.

В газовых скважинах Медвежьего и Уренгойского месторождений была апробирована технология плунжерного лифта постоянного действия для лифтовой колонны диаметром 168 мм. На кустах скважин электричество отсутствует, поэтому была испытана технология постоянного действия с помощью специальной конструкции плунжера «летающий клапан». В скважину помещается плунжер, представляющий собой цилиндрический корпус и шар. Плунжер на забое соединяется с шаром и поднимает столб жидкости, находящийся над ним. На устье скважины жидкость попадает в шлейф. За счет верхнего ограничителя ходя плунжера происходит разделение корпуса и шара, и они опять падают на нижний ограничитель. Соединившись, плунжер вместе с шаром поднимается к устью скважины. Цикл повторяется. 
Применение технологии плунжерного лифта имеет некоторые ограничения:

При скоростях газа менее 2 м/с, во время подъема плунжера
велика вероятность, что на верхнем ограничителе не про-
изойдет разделения шара с корпусом, что вызовет его зави-
сание в верхней части скважины;
Устойчивая работа плунжерного лифта на сегодняшний
день возможна лишь в скважинах с углами наклона не бо-
лее 30 градусов;
Имеющиеся сужения в НКТ могут вызвать застревание
плунжера, что вызовет необходимость проведения ремон-
тньх работ на скважине.

\section{Циклическая закачка сухого газа в затрубное пространство}

Газ высокого давления с выхода ДКС через промысловый шлейф поступает в затрубное пространство скважины. В результате суммарный расход газа, поступающего на забой скважины из пласта и через затрубное пространство с устья, становится выше критического и происходит вынос жидкости из скважины. Высокий удельный расход газа, необходимость в предварительной его подготовке и компримировании, а также наличие системы дополнительных газлифтных трубопроводов, являются основными факторами ограничения применения газлифта на газовых скважинах.

\section{Применение устьевых компрессорных установок}

Для поддержания технологического режима работы скважин независимо от давления на входе в ДКС, перспективным решением являются модульные компрессорные установки (МКУ), которые позволяют поднять входные давления на ДКС и продлить тем самым работу промыслов в целом. В настоящее время МКУ прошли апробацию на Вынгапуровском месторождении и проектируются на многих газовых месторождения ЯНАО. Внедрение подобных установок с их размешением на кустовых площадках имеет ряд достоинств: удобство в техническом обслуживании; легкость в транспортировке; неприхотливость в отношении климатических условий работы; вариативность в выборе установок с необходимыми производительными характеристиками и элементами компоновок, исходя из условий работы.

\section{Эксплуатация скважин с использованием концентрического лифта}

Технология эксплуатации скважин по конщентрическим лифтовым колоннам заключается в оборудовании скважины двумя размещенными одна в другой колоннами лифтовых труб. На забое газ, поступающий 
из пласта в скважину, разделяется на два потока и поднимается до устья, где потоки газа объединяются и поступают в единый газосборный коллектор. На трубопроводе из межтрубного пространства устанавливается регулирующий клапан, его задача автоматически поддерживать в межтрубном пространстве значение дебита газа, превышающего на 10-20\% минимальное значение дебита газа, необходимого для удаления жидкости с забоя по центральной лифтовой колонне.

Важнейший недостаток технологии конщентрического лифта, когда применяются металлические трубы - это необходимость глушения скважины и вытекающее негативное воздействие на ПЗП технологической жидкостью, а также длительный простой скважины (от 1 до 3 месяцев) со значительными капитальными затратами (более 20 млн рублей). Последующий выход скважины на рабочий режим может растянуться на месяцы, не исключается невозможность достижение доремонтной продуктивности. Однако эффективность технологии конщентрического лифта может быть значительно выше, если решить задачу реализации спуска дополнительной лифтовой колонны без проведения капитального ремонта и глушения. Повысить эффективность технологии позволяет применение цельных полимерных армированных труб, которые с помощью колтюбинговых технологий спускаются в скважину одним отрезком без глушения. Это позволяет многократно снизить трудоемкость и стоимость работ, устранить необходимость в глушении и освоении скважины и как следствие, предотвратить негативное воздействие на окружающую среду.

\section{РЕЗУЛЬТАТЫ ИССЛЕДОВАНИЙ И ИХ ОБСУЖДЕНИЕ}

Технология эксплуатации скважин по концентрическим лифтовым колоннам (КЛК), представляет собой процесс, в котором поступающий из продуктивного пласта газ на забое разделяется на два восходящих потока. Для этого в уже имеющуюся насосно-компрессорную трубу (НКТ) спускают еще одну лифтовую колонну меньшего диаметра. Таким образом, потоки поднимаются одновременно по межколонному пространству труб и по центральной колонне. После подъема газа к устью скважины, потоки соединяются и поступают в единый газосборный коллектор. Суть технологии заключается в том, что появляется возможность за счет уменьшения скорости восходящего потока по межколонному пространству, увеличить скорость потока в центральной лифтовой колонне. То есть когда скорость снижается и подходит к критическому значению, предшествуюшему процессу самопроизвольной остановки скважины по причине накопления воды, скорость в центральной колонне повышают до значения, предотвращающего это событие. Выполняет это действие автоматика. 
Первые применения технологии конщентрического лифта относятся еше к периодам с 60-х по 90-е годы на Северо-Ставропольском, Газлийском, Шебелинском и других газовых месторождений, расположенных в средней полосе с умеренным климатом. Широко применяется технология на месторождениях Канады, где разработан управляющий комплекс «Smart-Skid». Этот комплекс позволяет: автоматизировано управлять процессом оптимизации режима работы газовой скважины; определять основные величины технологических параметров работы скважин; размещать средства считывания относительных параметров автоматики и телемеханики вблизи устья скважины и установки в составе обвязки газовых скважин. Технология прошла апробацию на двух скважинах Медвежьем месторождении в 2008 году.

Конструктивные особенности скважин на Медвежьем месторождении, оборудованных по технологии концентрического лифта представляют собой следующее: скважины вертикальные, с эксплуатационной колонной 219 мм, лифтовой внешней 168 мм, дополнительно спущенной (центральной) 60 мм.

С 2012 года технология концентрического лифта используется на одной из скважин Ямбургского месторождения. Для регулирования и контроля режима работы скважины используется специальный комплекс «Вымпел». В отличие от оборудования, используемого на скважинах Медвежьего месторождения, в составе комплекса нет песчаных фильтров и отапливаемого блокбокса. Все основные элементы: расходомеры, регулирующие клапана, контроллеры размешены в автономных утепленных боксах. В процессе опытной эксплуатации скважин по КЛК и оборудования управляющих комплексов на месторождениях наблюдались сложности, связанные с глушением скважин на период установки центральных колонн, засорение фильтрующих элементов песчаных фильтров из-за выноса большого количества песка и технического раствора.

В настоящее время эти недочеты решены и в течение последних нескольких лет сбоев в работе скважин и отказов оборудования не происходило. Чтобы исключить сложности в освоении обусловленные последствиями глушения скважин сеноманских залежей на период спуска центральной лифтовой колонны в настоящее время в ОАО «Псковгеокабель» разработаны и изготовлены труба и устройства для её спуска в скважину без глушения. Апробацию разработанный комплекс проходил на Уренгойском месторождении.

Особенностью реализации данной технологии на Уренгойском месторождении был спуск центральной лифтовой колонны в скважину без глушения единым отрезком. Обойти необходимости глушения скважины удалось с помощью применения подхода, аналогичного методу проведения ремонтов скважин колтюбинговыми технологиями с использованием гибкой трубы без соединительных муфт, которая спускается до забоя скважины единым отрезком. Также для спуска трубы ООО «Псковгеокабель» и ООО НИП «ДельтаТ» разработали и изготовили комплекс оборудования МКРС-20 для спуска 


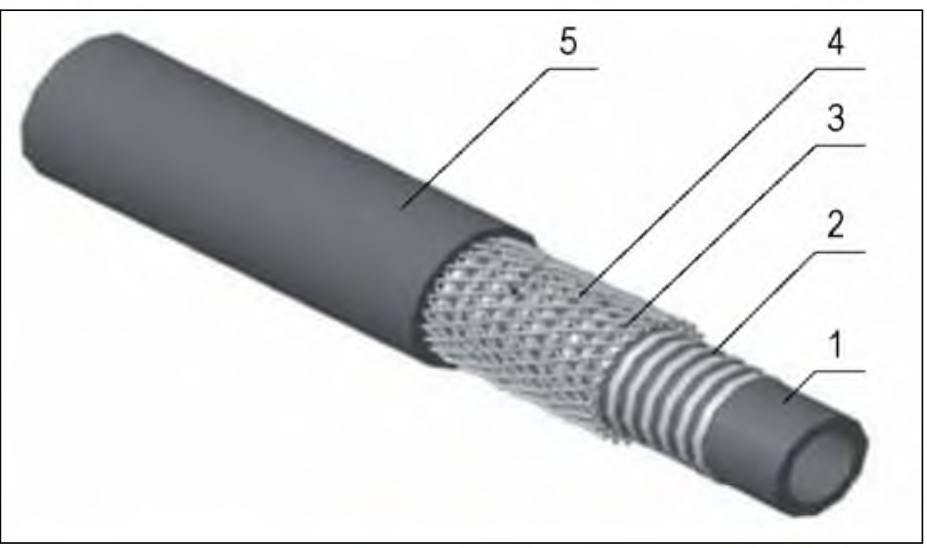

б)

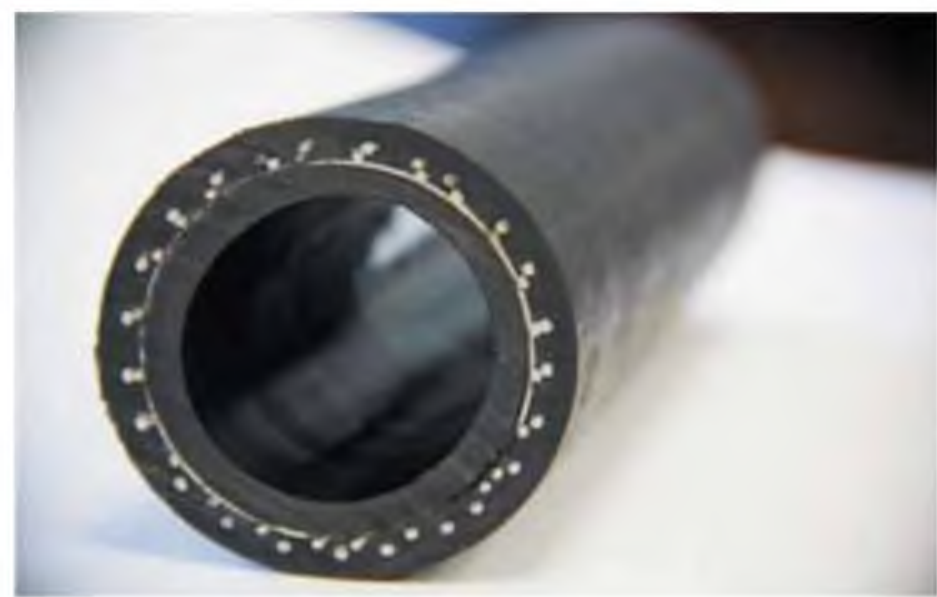

Рис 2.

\section{Полимерная армированная труба ТГ19/73-10/10-75:}

а) конструкция трубы;

б) фотография трубы: 1 - внутренняя полимерная труба, 2 - поперечное армирование, 3, 4 - поливы брони (левый, правый), 5 - наружная оболочка.

Fig. 2. Polymer reinforced pipe T G 19/73-10/10-75: a) pipe design; b) pipe photo: 1 - inner polymer pipe, 2 - transverse reinforcement, 3, 4-armor watering (left, right), 5 - outer shell.

этой трубы, состоящий из следующих элементов: трубодержателя для КЛК; превентора; герметизатора; инжектора (податчика); вышки для монтажа инжектора; приемно-отдающего устройства; технологической штанги; гидростанции с системой управления.

В декабре 2013 года скважина была запущена в опытно-промышленную эксплуатацию. Результаты газогидродинамических исследований скважин (ГДИС) показали, что коэффициент фильтрационного сопротивления 
призабойной зоны пласта практически не изменился после спуска конщентрической лифтовой колонны.

Результаты расчета скоростей восходящего потока на режимах ГДИС скважины, оборудованной концентрической лифтовой колонной, и оценочные расчеты скоростей при работе скважины по НКТ 168 мм или НКТ 114 мм показывают, что без оборудования КЛК устойчивая работа скважины в газосборный коллектор невозможна. При работе по НКТ 168 мм скорость газа позволяет выносить жидкость лишь на режиме с максимальной депрессией. Для лифтовой колонны диаметром 114 мм продуктивность скважины не обеспечивает устойчивый вынос жидкости из скважины на всех режимах. Уменьшение диаметра НКТ привело к снижению дебита скважины из-за увеличения гидравлического сопротивления в лифтовом подъемнике.

\section{выводы}

Наиболее перспективными техническими решениями по эксплуатации скважин на завершающей стадии разработки являются закачка ПАВ на забой, применение модульных компрессорных установок, позволяющих регулировать технологический режим работы скважин независимо от давления на входе в ДКС и применение концентрического лифта с армированными полимерными трубами без глушения скважины. Внедрение технологии концентрического лифта обеспечивает стабильную работу скважины без технологических продувок и высокую работоспособность в широком диапазоне дебитов. Технологический комплекс контроля и управления работой скважины обеспечивает надежную эксплуатацию в условиях Крайнего Севера. Применение технологии эксплуатации скважин по концентрическим лифтовым колоннам перспективно на поздней и завершающей стадиях разработки газовых месторождений.

\section{БИБЛИОГРАФИЧЕСКИЙ СПИСОК}

1. Колмаков А.В., Кротов П.С., Кононов А.В. Технологии разработки сеноманских залежей низконапорного газа // СПб.: Недра, 2012. $176 \mathrm{C}$.

2. Ли Джеймс, Никенс Генри, Уэллс Майкл Эксплуатация обводняющихся газовых скважин. Технологические решения по удалению жидкости из скважин // Перевод с английского. М.: Премиум Инжиниринг, 2008. 384 с., ил. (Промышленный инжиниринг).

3. Корякин А.Ю. Комплексные решения задач разработки и эксплуатации скважин Уренгойского добывающего комплекса // М., 2016. 272 c.

4. Точигин А.А. Одишария Г.Э. Прикладная гидродинамика газожидкостных смесей // М.: Газпром ВНИИГАЗ; Ивановский государственный энергетический университет, 1998. 400 с.

5. Саранча А.В., Хабибуллин А.Ф., Огай В.А. Удаление пластовой 
и конденсационной воды с забоев газовых скважин на основе закачки азота. // В сборнике: Новые технологии нефтегазовому региону. Материалы международной научно-практической конференции. Тюмень, 2016. С. 191-193.

6. Овечкина Е.С., Левитина Е.Е. Технологии эксплуатации обводняющихся газовых скважин // В сборнике: Новые технологии нефтегазовому региону. Материалы международной научнопрактической конференции. Тюмень. 2016. с. 149-154.

7. Дикамов Д.В., Минликаев В.3., Мазанов С.В., Имшенецкий М.А., Шулятиков И.В. Устьевое оборудование для эксплуатации скважин Ямбургского месторождения по концентрическим лифтовым колоннам /НЕФТЕГАЗ. №1. 2009. С55.

8. McLAURY, B.S., S.A. SHIRAZI, J.R. SHADLEY. A particle tracking method to predict sand erosion threshold velocities in elbow and tees. In: Proc. of the 1994 ASME Fluids Engineering Division summer meeting, Lake Tahoe, Nevada, June 19-23, 1994.

\section{References}

1. Kolmakov, A. V., Krotov P. S., Kononov A.V. The technology development of the Cenomanian deposits of low-pressure gas, $\mathrm{SPb}$ : NEDRA LLC, 2012. 176 pages.

2. Lee James, Nickens Genry, Wells Michael Operation of waterlogged gas wells. Technological solutions for the removal of fluid from wells // Translation from English. M.: LLC "Premium Engineering" 2008. 384 pages.

3. Koryakin, A. Yu. Complex solutions of problems of development and operation of wells of the Urengoy mining complex // M., 2016. 272 pages.

4. Torchigin, A. A., Odisharia, G. E. Applied hydrodynamics of gasliquid mixtures, Moscow: Gazprom VNIIGAZ; Ivanovo state power University, 1998. 400 pages.

5. Sarancha, A. V., Khabibullin, A. F., Ogay, V. A. The formation and removal of condensation water from the bottom of gas wells based on the injection of nitrogen, In the collection: New technologies for the oil and gas region. Materials of scientific and practical international conference. Tyumen. 2016. pp. 191-193.

6. Ovechkina, E. S., Levitina, E. E. Technology exploitation of water gas wells, In the collection: New technologies for the oil and gas region. Materials of scientific and practical international conference. Tyumen. 2016. pp. 149-154.

7. Dikamov, D. V., In Minlikaev, V. Z., Mazanov, S. V., Imshenetsky M. A., and Shulyatikov, I. B. Wellhead equipment for the operation of wells Yamburg field on concentric lift columns, NEFTEGAS, No.1, 2009. p. 55.

8. McLAURY, B.S., S.A. SHIRAZI, J.R. SHADLEY. A particle tracking method to predict sand erosion threshold velocities in elbow and tees. In: Proc. of the 1994 ASME Fluids Engineering Division summer meeting, Lake Tahoe, Nevada, June 19-23, 1994. 
Рукопись поступила в редакцию 05.07.2019, принята к публикации 02.09.2019

\section{6 авторах}

Саранча Алексей Васильевич, к.Т.н. доцент кафедры «Разработка и эксплуатация нефтяных и газовых месторождений» Тюменского индустриального университета, тел. 89829270878,

E-mail: saranchaav@tyuiu.ru

Левитина Екатерина Евгеньевна, к.Т.н. доцент кафедры «Разработка и эксплуатация нефтяных и газовых месторождений» Тюменского индустриального университета, тел. 89044934964, E-mail: levitinaee@tyuiu.ru

Есиков Сергей Николаевич, преподаватель Тюменского индустриального университета, тел. 89199554503,

E-mail: esikovsn@tyuiu.ru

\section{About the authors}

Sarancha Alexey, Ph. D., associate Professor of the Department "Development and operation of oil and gas fields" of Tyumen industrial University, tel.89829270878, E-mail: saranchaav@tyuiu.ru

Levitina Ekaterina, Ph. D., associate Professor of the Department "Development and operation of oil and gas fields" of Tyumen industrial University, tel.89044934964, E-mail: levitinaee@tyuiu.ru

Esikov Sergey Nikolaevich, teacher of Tyumen industrial University, tel. 89199554503, E-mail: esikovsn@tyuiu.ru 